\title{
Risk factors associated with diabetic retinopathy in patients with diabetes mellitus type 2
}

\author{
Irini P Chatziralli*1, Theodoros N Sergentanis², Petros Keryttopoulos ${ }^{3}$, Nikolaos Vatkalis ${ }^{3}$, Antonis Agorastos ${ }^{3}$ and \\ Leonidas Papazisis ${ }^{1}$
}

\begin{abstract}
Background: Diabetes mellitus (DM) is associated with microvascular complications, such as diabetic retinopathy (DR). DR is one of the main causes of visual loss in individuals aged 20-64 years old. This study aims to investigate the independent associations between the stage of DR and a variety of possible risk factors, including years since DM diagnosis, $\mathrm{HbA}_{1 \mathrm{c}}$ levels, the coexistence of hypertension, age and gender.

Findings: 120 patients were recruited in the Department of Internal Medicine, Veroia General Hospital, Veroia, Greece, and the DR stage was defined by an ophthalmologist. Afterwards, the DR association with the aforementioned factors was examined. Univariate and multivariate analysis (multivariate ordinal logistic regression) was performed. At the univariate analysis, there was a positive association between DR severity and age (Spearman's rho $=0.4869, p<0.0001$ ), years since DM diagnosis (Spearman's rho $=0.6877, \mathrm{p}<0.0001$ ), $\mathrm{HbA}_{1 \mathrm{c}}$ levels (Spearman's rho $=0.6315, \mathrm{p}<0.0001$ ), history of hypertension ( $2.47 \pm 1.37$ vs. $0.50 \pm 0.80$ for patients without hypertension; $p<0.0001)$ and male sex $(2.56 \pm$ 1.41 vs. $2.05 \pm 1.45$ for female patients; $p=0.045, \mathrm{MWW}$ ). All these factors, except for age, retained their statistical significance at the multivariate ordinal logistic model.
\end{abstract}

Conclusions: Years since DM diagnosis, hypertension, $\mathrm{HbA}_{1 \mathrm{c}}$ levels and male sex are independently associated with severe DR. The effect of age seems to reflect a confounding association.

\section{Background}

Diabetes mellitus (DM) is associated with microvascular complications, such as diabetic retinopathy (DR). DR is one of the main causes of visual loss in individuals aged 20-64 years old [1] and is present in more than $77 \%$ of patients with DM type 2 who survive for over 20 years with the disease [2]. Many factors have been associated with the progression and severity of DR, such as DM duration $[3,4]$, the control of serum glucose levels [4-6], hypertension $[4,7]$ or gender [4]. So far the most solid evidence concerning the risk of DR pertains to chronic hyperglycemia; interestingly, in insulin users with DM type 2 (i.e., more severe cases), DR occurs in approximately $84.5 \%$ of patients after 15 years of the disease [6,8]. In this study, we aim to investigate the independent associations between the stage of DR and a variety of risk fac-

\footnotetext{
* Correspondence: eirchat@yahoo.gr

1 Department of Ophthalmology, Veroia General Hospital, Veroia, Greece Full list of author information is available at the end of the article
}

tors, including years since $\mathrm{DM}$ diagnosis, $\mathrm{HbA}_{1 \mathrm{c}}$ levels, the coexistence of hypertension, age and gender.

\section{Materials and methods}

120 consecutive patients with type $2 \mathrm{DM}$ (56 men and 64 women) participated in the study (age range: $42-89$ years old, median: 73.5 years). All consecutive patients were recruited (during their routine follow-up) in the Department of Internal Medicine, Veroia General Hospital, Veroia, Greece, during the time period April 2009 to September 2009. A person was considered as known diabetic, if there was an informational letter from a diabetologist. All participants underwent a comprehensive dilated fundus examination to detect DR by indirect ophthalmoscopy. DR was clinically graded in accordance with the International Clinical Diabetic Retinopathy guidelines [9]. The examined risk factors included demographic and clinical parameters. The demographic risk factors studied were age and gender. The clinical factors 


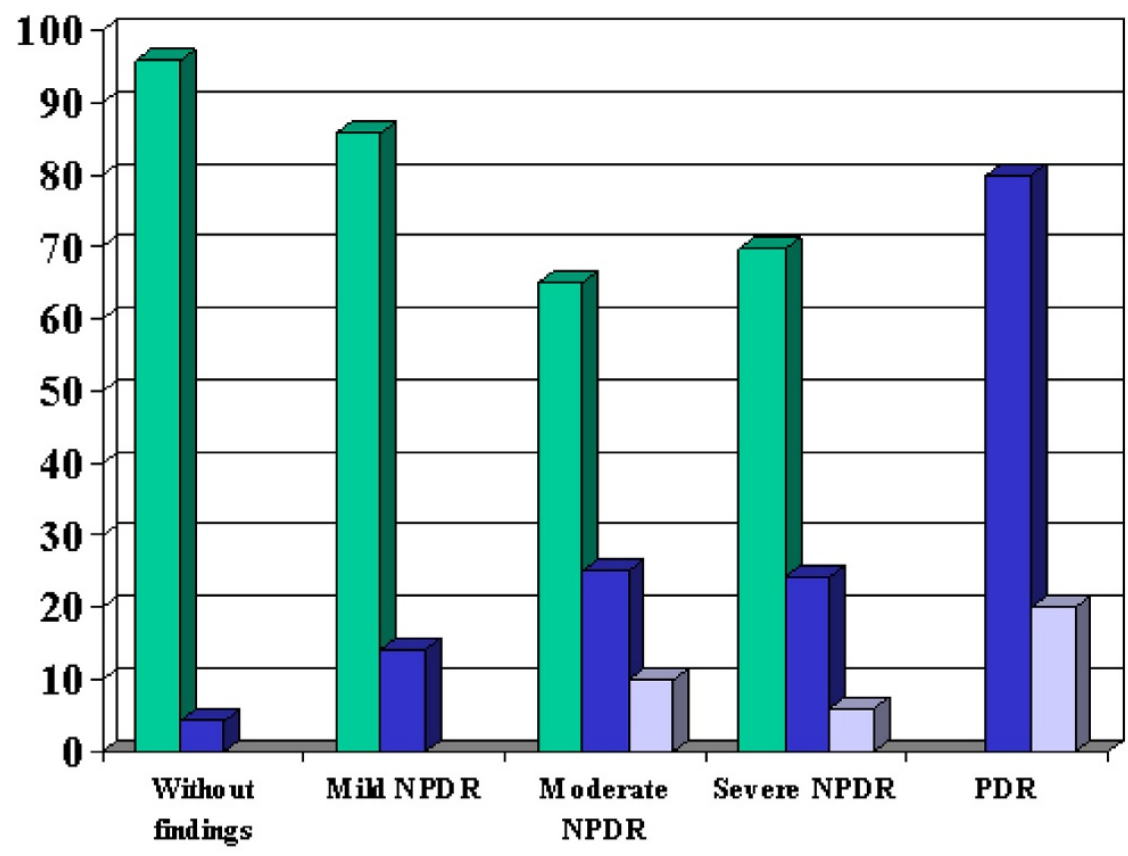

$\square$ HbA1c $<7$
$\square$ HbA1c $: 7-8.5$
$\square$ HbA1c $>8.5$

Figure $1 \mathrm{Graph}$ presenting the positive association between the severity of $\mathrm{DR}$ and $\mathrm{HbA}_{1 \mathrm{c}}$ levels.

were the following: years since diagnosis of $\mathrm{DM}, \mathrm{HbA}_{1 \mathrm{c}}$ levels and coexistence of hypertension.

The severity of DR was treated as an ordinal variable. Specifically, 0: without findings, 1: mild non-proliferative DR, 2: moderate non-priliferative DR, 3: severe non-proliferative DR, 4: proliferative DR. Similarly, the variable concerning years since diagnosis of DM was treated as an ordinal variable (0: $0-5$ years, $1: 5-10$ years, $2: 10-15$ years, 3: $15-20$ years, $4:$ more than 20 years). Accordingly, $\mathrm{HbA}_{1 \mathrm{c}}$ levels were treated as an ordinal variable $(0:<7 \%, 1: 7$ $8.5 \%, 2:>8.5 \%$ ).

The statistical analysis encompassed two steps: univariate and multivariate analysis. At the univariate analysis, the associations between the severity of DR and the study variables (age, gender, $\mathrm{HbA}_{1 \mathrm{c}}$ levels, years since diagnosis of DM and hypertension) were appropriately evaluated through non-parametric statistics (Mann-Whitney-Wilcoxon test for independent samples, designated as MWW for reasons of brevity, or Spearman's rank correlation coefficient).

At the multivariate analysis, multivariate ordinal logistic regression was performed. The severity of DR was treated as the dependent variable. The variables which were proven significant at the univariate analysis were entered as independent variables in the model; backward selection of variables was performed so as to reach the most parsimonious model. The satisfaction of the proportionality-of-odds assumption was assessed with the appropriate likelihood ratio test. Statistical analysis was performed with STATA 8.0 statistical software (Stata Corporation, College Station, TX, USA).

This study is in accordance with the Declaration of Helsinki and has been approved by the local Ethics Committee. Written informed consent was obtained from all patients. The authors declare no conflict of interest.

\section{Results}

At the univariate analysis, the severity of DR was positively associated with patients' age (Spearman's rho = $0.4869, \mathrm{p}<0.0001$ ), years since DM diagnosis (Spearman's rho $=0.6877, \mathrm{p}<0.0001$, Table 1$), \mathrm{HbA}_{1 \mathrm{c}}$ levels (Spearman's rho $=0.6315, \mathrm{p}<0.0001$, Figure 1$)$. Male patients exhibited more advanced DR $(2.56 \pm 1.41$ vs. 2.05 \pm 1.45 for female patients; $\mathrm{p}=0.045$, MWW). Patients with coexisting hypertension presented with more severe DR $(2.47 \pm 1.37$ vs. $0.50 \pm 0.80$ for patients without hypertension; $\mathrm{p}<0.0001, \mathrm{MWW})$.

The results of the multivariate ordinal logistic regression are presented in Table 2. All variables, except for age, retained their statistically significant associations with the severity of DR at the multivariate approach.

\section{Discussion}

The duration of DM appears as a meaningful predictor for DR and its severity $[3,4,10]$ however, cases free of DR are occasionally reported despite long duration of DM [8]. Carefully examining the descriptive statistics of our study sample, it is astonishing that $45.8 \%$ of patients who were diagnosed with DM twenty or more years ago 
Table 1: Detailed results on the association between the severity of DR and years since diagnosis of DM.

\begin{tabular}{|c|c|c|c|c|c|}
\hline \multirow{3}{*}{ Diabetic Retinopathy stage } & \multicolumn{5}{|c|}{ Duration of DM } \\
\hline & $0-5$ years & $5-10$ years & 10-15 years & $15-20$ years & $>20$ years \\
\hline & $n=18$ & $n=10$ & $n=18$ & $\mathbf{n}=\mathbf{2 6}$ & $n=48$ \\
\hline Without findings & $88.9 \%(16 / 18)$ & $40 \%(4 / 10)$ & $16.7 \%(3 / 18)$ & & \\
\hline Mild Non-Proliferative DR & $11.1 \%(2 / 18)$ & $40 \%(4 / 10)$ & $27.8 \%(5 / 18)$ & & $6.3 \%(3 / 48)$ \\
\hline Moderate Non-proliferative DR & & $20 \%(2 / 10)$ & $22.2 \%(4 / 18)$ & $11.5 \%(3 / 26)$ & $22.9 \%(11 / 48)$ \\
\hline Severe Non-proliferative DR & & & $22.2 \%(4 / 18)$ & $\begin{array}{l}65.4 \%(17 / \\
26)\end{array}$ & $25.0 \%(12 / 48)$ \\
\hline Proliferative DR & & & $11.1 \%(2 / 18)$ & $23.1 \%(6 / 26)$ & $45.8 \%(22 / 48)$ \\
\hline
\end{tabular}

exhibit proliferative DR; on the contrary, $88.9 \%$ of patients who have been diagnosed with DM since 0-5 years are free of DR.

The role of chronic hyperglycemia in the development of DR has also been well established [4-6]. High $\mathrm{HbA}_{1 \mathrm{c}}$ levels are closely associated with severe DR in our study. Decrease in $\mathrm{HbA}_{1 \mathrm{c}}$ concentrations by $1 \%$ leads to an estimated reduction of $30 \%$ in the risk of microvascular complications [8].

Hypertension is an important risk factor for the onset and progression of the disease, and in most studies it is an independent risk factor for DR $[4,6,7,10]$. The UK Prospective Diabetes Study (UKPDS) demonstrated that blood pressure control is associated with a reduction in DR incidence; the relative risk for DR is 1.5 concerning systolic pressure between $125-139 \mathrm{mmHg}$ and 2.8 for systolic pressure higher than $140 \mathrm{~mm} \mathrm{Hg}$ [6].

In our study, male patients exhibited more advanced DR; this finding seems distinct than that reported by previous studies, according to which male gender was related with the presence of DR, but not its severity $[4,10]$.

Concerning the role of age, it is worth commenting on our study findings. Age was associated with the severity of DR at the univariate analysis but lost its significance at the multivariate model. Most probably, this reflects a confounding effect of age, as older age and longer duration of DM are two factors closely associated with each other. As a result, age does not seem to represent an independent risk factor for severe DR.

A limitation of the present study was that DR grading was based on fundoscopy and not on fundus photography grading. This could have resulted in underestimation of the prevalence and severity of DR. In addition, a considerable limitation of this study pertains to the relatively small sample size; nevertheless, the fact that the results persisted at the multivariate approach points to the validity of the findings presented herein.

\section{Conclusions}

In conclusion, this study demonstrates that male gender, coexistence of hypertension, years since diagnosis of DM and $\mathrm{HbA}_{1 \mathrm{c}}$ represent independent risk factors for severe DR.

\section{List of abbreviations}

DM: Diabetes Mellitus; DR: Diabetic Retinopathy; MWW: Mann-Whitney-Wilcoxon; UKPDS: UK Prospective Diabetes Study.

Table 2: Results of the multivariate ordinal logistic regression

\begin{tabular}{llll}
\hline Variables & Category or increment & OR (95\% CI) & p-value \\
\hline Gender & Male vs. Female & $3.57(1.67-7.62)$ & 0.001 \\
Hypertension & Yes vs. No & $4.49(1.15-17.49)$ & 0.030 \\
Years since diagnosis of DM & 1 level increase & $3.37(2.34-4.85)$ & $<0.001$ \\
$\mathrm{HbA}_{1 \mathrm{c}}$ & 1 level increase & $4.53(2.11-9.72)$ & $<0.001$ \\
\hline
\end{tabular}




\section{Competing interests}

The authors declare that they have no competing interests.

\section{Authors' contributions}

IPC conceived the idea of the study, designed the study, performed fundoscopy and drafted the manuscript. TNS performed the statistical analysis and drafted the manuscript. PK participated in the design of the study and drafted the manuscript. NV participated in the recruitment of patients and revised the manuscript critically for important intellectual content. AA participated in data collection and revised the manuscript critically for important intellectual content. LP participated in the design of the study and its coordination, helped to draft the manuscript and has given final approval of the version to be published. All authors read and approved the final manuscript.

\section{Author Details}

'Department of Ophthalmology, Veroia General Hospital, Veroia, Greece,

${ }^{2} \mathrm{Sch}$ col of Medicine, National University of Athens, Greece and ${ }^{3}$ Department of Internal Medicine, Veroia General Hospital, Veroia, Greece

Received: 27 March 2010 Accepted: 1 June 2010

Published: 1 June 2010

\section{References}

1. Centers for Disease Control and Prevention (CDC): Blindness caused by diabetes--Massachusetts, 1987-1994. MMWR Morb Mortal Wkly Rep 1996, 45:937-941.

2. Wild S, Roglic G, Green A, Sicree R, King H: Global prevalence of diabetes: Estimates for the year 2000 and projections for 2030. Diabetes Care 2004, 27:1047-1053.

3. Bamashmus MA, Gunaid AA, Khandekar RB: Diabetic retinopathy, visual impairment and ocular status among patients with diabetes mellitus in Yemen: a hospital-based study. Indian J Ophthalmol 2009, 57:293-298.

4. Rani PK, Raman R, Chandrakantan A, Pal SS, Perumal GM, Sharma T: Risk factors for diabetic retinopathy in self-reported rural population with diabetes. J Postgrad Med 2009, 55:92-96

5. Rodriguez-Fontal M, Kerrison JB, Alfaro DV, Jablon EP: Metabolic control and diabetic retinopathy. Curr Diabetes Rev 2009, 5:3-7.

6. UK Prospective Diabetes Study (UKPDS) Group: Effect of intensive bloodglucose control with metformin on complications in overweight patients with type 2 diabetes (UKPDS 34). Lancet 1998, 352:854-865.

7. Wang $S$, Xu L, Jonas JB, Wong TY, Cui T, Li Y, Wang YX, You QS, Yang H, Sun C: Major Eye Diseases and Risk Factors Associated with Systemic Hypertension in an Adult Chinese Population The Beijing Eye Study. Ophthalmology 2009, 116:2373-2380.

8. Esteves J, da Rosa CM, Kramer CK, Osowski LE, Milano S, Canani LH: Absence of diabetic retinopathy in a patient who has had diabetes mellitus for 69 years, and inadequate glycemic control: case presentation. Diabetol Metab Syndr 2009, 1:13

9. Wilkinson CP, Ferris FL, Klein RE, Lee PP, Agardh CD, Davis M, Dills D, Kampik A, Pararajasegaram R, Verdaguer JT: Global Diabetic Retinopathy Project Group. Proposed international clinical diabetic retinopathy and diabetic macular edema disease severity scales. Ophthalmology 2003, 110:1677-1682.

10. Pradeepa R, Anitha B, Mohan V, Ganesan A, Rema M: Risk factors for diabetic retinopathy in a South Indian Type 2 diabetic population--the Chennai Urban Rural Epidemiology Study (CURES) Eye Study 4. Diabet Med 2008, 25:536-542.

doi: $10.1186 / 1756-0500-3-153$

Cite this article as: Chatziralli et al., Risk factors associated with diabetic retinopathy in patients with diabetes mellitus type 2 BMC Research Notes 2010, 3:153

\section{Submit your next manuscript to BioMed Centra and take full advantage of:}

- Convenient online submission

- Thorough peer review

- No space constraints or color figure charges

- Immediate publication on acceptance

- Inclusion in PubMed, CAS, Scopus and Google Scholar

- Research which is freely available for redistribution

Submit your manuscript at www.biomedcentral.com/submit
C BioMed Central 